\title{
Effect of social integration on childbirth return among internal migrant pregnant women: a nationally representative study in China
}

Lulu Ding ${ }^{1+}$, Xinying $\mathrm{Li}^{2+}$, Xue Tang ${ }^{1}$, Yuejing Feng ${ }^{1}$, Yi Wang $^{1}$, Jiejie Cheng ${ }^{2}$, Mei Sun ${ }^{2^{*}}$ and Chengchao Zhou ${ }^{1,3^{*}}$ (I)

\begin{abstract}
Background: Social integration has been demonstrated to be associated with the health care use among migrants, but few studies have focused on migrant pregnant women. This study aims to explore the association between social integration and childbirth at woman's hometown (childbirth return) of internal migrant pregnant women in China.

Method: Using the data of "Monitoring Data of Chinese Migrants" in 2014, a total of 3412 internal migrant pregnant women were included in this study. Social integration was measured by economic integration, acculturation, and identification. The childbirth locations of internal migrant pregnant women were divided into current residency and the woman's hometown. Univariate logistic regression and two multivariable logistic regression models were employed to assess the association between social integration and childbirth return among internal migrant pregnant women.

Result: Our study finds that $24.56 \%$ of migrant pregnant women choose to have a childbirth return. As for social integration, those who have their own house $(\mathrm{OR}=0.35195 \% \mathrm{Cl} 0.207-0.595)$ in current residence, who have been staying in current residence for at least 5 years $(\mathrm{OR}=0.449 ; 95 \% \mathrm{Cl} 0.322-0.626)$, and who are willing to stay in the current residence for a long time $(\mathrm{OR}=0.731 ; 95 \% \mathrm{Cl} 0.537-0.995)$ are less likely to have a childbirth return. Apart from social integration, our results also show that those migrant pregnant women who are older, who have higher education level, who have at least two family members in current residence, with a migration reason of work and business, who have established health record in the current residency, and who were not covered by medical insurances, are less likely to have a childbirth return.
\end{abstract}

Conclusion: Social integration is negatively associated with childbirth return among internal migrant pregnant women in China. To improve the utilization of maternal care services for migrant pregnant women in current residence, targeted policies should be made to improve social integration status for migrant pregnant women.

Keywords: Internal migrant women, Childbirth return, Social integration

\footnotetext{
* Correspondence: sunmei@fudan.edu.cn; zhouchengchao@sdu.edu.cn

${ }^{\dagger}$ Lulu Ding and Xinying Li contributes equally to this study and is a co-first author of the paper.

${ }^{2}$ School of Public Health, Fudan University, Shanghai 200032, China

${ }^{1}$ Centre for Health Management and Policy, School of Public Health, Cheeloo

College of Medicine, Shandong University, Jinan 250012, China

Full list of author information is available at the end of the article
}

(c) The Author(s). 2020 Open Access This article is licensed under a Creative Commons Attribution 4.0 International License, which permits use, sharing, adaptation, distribution and reproduction in any medium or format, as long as you give appropriate credit to the original author(s) and the source, provide a link to the Creative Commons licence, and indicate if changes were made. The images or other third party material in this article are included in the article's Creative Commons licence, unless indicated otherwise in a credit line to the material. If material is not included in the article's Creative Commons licence and your intended use is not permitted by statutory regulation or exceeds the permitted use, you will need to obtain permission directly from the copyright holder. To view a copy of this licence, visit http://creativecommons.org/licenses/by/4.0/. The Creative Commons Public Domain Dedication waiver (http://creativecommons.org/publicdomain/zero/1.0/) applies to the data made available in this article, unless otherwise stated in a credit line to the data. 


\section{Background}

In China, the number of internal migrant population had increased from 230 million in 2011 to 244 million in 2017 , which occupies a large proportion of nearly $18 \%$ of the total population [1]. The rapid expanding of migrant population scale promotes economic prosperity, but also brings a number of public health issues, including problems in infectious diseases, childhood immunization, mental health, maternal healthcare etc. [2-5] In the past decades, with the emergence of "family migration style", more and more fertile women outmigrated with their husbands, and the number of migrant fertile women is on the rapid rise, accounting for over $30 \%$ of the total migrant population $[6,7]$. Consequently, migrant maternal healthcare use is an important issue deserves attention.

From the perspective of inflow area, social integration is found to be an important factor associated with health service use among the migrants [8]. Social integration refers to the process during which migrants are incorporated into the social structure of the society in inflow areas. Although different scholars have different definitions and measurements of social integration, they all share certain dimensions: economic integration, acculturation, and identification [9-11]. A study by Kemppainen et al. about the health utilization by immigrants in Russia found that stronger social integration predicted less frequent return for health care utilization [12]. In some countries, such as South Korea, special policies have been developed to improve social integration, so as to promote health status among migrant fertile women [13].

Pregnancy is a critical period, not only for the pregnant woman and her unborn child, but also for her whole family. Mobility during pregnancy is found to be linked to poor health outcomes of pregnant mothers and infants or unborn child [14]. Residential instability during pregnancy brings environmental change which was found to be associated with congenital anomalies [15-17]. There are some other studies indicating that mobility during pregnancy may lead to decreased use of maternal healthcare services due to less knowledge and information, or other barriers to accessibility of health service $[18,19]$. Some previous studies found that mobility during pregnancy was detrimental to healthcare provision, which was due to the failure to address the scale and traits of the migrant pregnant women and their specific demands [20, 21]. A series of policies, such as promoting the equalization of public health services' [22-24] were developed to enable the migrants in the inflow areas to receive the same medical and public health services as local permanent residents. In addition, the China Women's Development Program 2011-2020 clearly states that migrant women should receive the same health care services as the women in the inflow areas [25]. Even so, previous studies have demonstrated that the migrants have poorer access to health care services in the inflow areas than that in local permanent residents [26]. As a coping style, some migrants would like to return their hometown for health care use. A previous study by Bergmark et al. showed that $46 \%$ Mexican immigrants reported they had a close friend or relative returned to Mexico from U.S. for health care use [27]. A similar study by Jiang also found that about one-fourth of the respondents have visited their home country for medical care since their migration to the US [28]. Similarly, there are also some relevant studies in China. A study by Song reported that $37.23 \%$ of 118 hospitalized migrants in Guangzhou had returned to their hometown for medical care [29]. Another study in Beijing reported that $63.16 \%$ of 114 migrant returned to their hometown for in-patient services [30]. Of the reasons for their returning hometown for health care use, preferring medical style of homeland or having social ties with homeland are the common ones that facilitate their return [31, 32].

In China, there are some studies focusing on migrants and social integration status, but mainly concentrating on the association between social integration and physical or psychological well-being of migrants [33, 34]. Few studies explored the migrants' return for healthcare use, and also very few studies focused on the association between social integration and healthcare use among the migrants. To date, no studies have explored the association between social integration and returning their hometown for childbirth (childbirth return) among internal migrant women in China. To remedy this situation, this study aims to explore the association between social integration and childbirth return among internal migrant pregnant women. To do so, we have several specific objectives. First, we will estimate the prevalence of childbirth return among migrant pregnant women. Second, we will explore the association between the social integration and childbirth return among internal migrant pregnant women in China.

\section{Methods}

\section{Data source}

The data were obtained from the "2014 National Internal Migrant Population Dynamic Monitoring Survey (NIMPDMS)", which was conducted by the National Health and Family Planning Commission of China. Inclusion criteria for the survey were adults living in the inflow areas for 1 month or longer without local Hukou registration (Hukou is the household registration system in China, which was divided into rural and urban in this study) and aged between 15 and 59 years as of May 2015. It was a nationally representative survey which was conducted in 32 provinces, municipalities, autonomous 
regions, and migrant gathering areas in Xinjiang Production and Construction Corps. A total of 431 cities were selected as sample sites. The survey used a stratified multi-stage sampling method with a probabilityproportional-to-size (PPS) approach to select participants [35]. Face-to-Face interviews were conducted by trained health staff in sampling communities. It took about $1 \mathrm{~h}$ for the interviewers to conduct each interview. The survey included respondents' demographic characteristics, their family members, employment status, housing, health care, marital status, obstetrical status. The total sample size was 206,000 people in 2014 , and the criteria of the sample selection in this study was that who gave birth in the past year before the survey. Finally, 3412 eligible internal migrant pregnant women were included in the analysis, and the sampling process is presented in the Additional file 1: Figure S1.

\section{Variables}

\section{Dependent variable}

The participants in this study are filtered by two questions: "Have you had used in-patient service in the past 12 months?" If the answer is "yes", then a second question of "What is the leading reason for your in-patient service?" Those women whose answer was "Hospital childbirth" were included in this study. The dependent variable of this study was defined by asking the respondents "Where was your hospital childbirth?" The answer was divided into two types, "returning their hometown", and "in the current residence".

\section{Independent variables}

Social integration Based on the previous literature, combining with the questionnaire used in the survey, the social integration in this study was mainly measured from the dimensions of economic integration, acculturation, and identification. Factors including employment status (unemployment and employment), household monthly income, and housing in the current residence (rent or borrow, own, others) were used to measure the dimension of economic integration. Duration of stay in current residence ( 5 years and below, and more than 5 years) was used to measure the dimension of acculturation. Willingness to stay for a long time (no and yes) was used to measure the dimension of identification. Here, we used the quartile method to divide household monthly income into four levels, Q1, Q2, Q3, and Q4. Quartile1(Q1) is the lowest (poorest) group and Quartile4(Q4) is the highest (richest) group.

Social demographic characteristics Social demographic characteristics include age, ethnic group, education level, family members in current residence, Hukou, migration range, the reason for migration, health record in current residence, and medical insurance. The participants' age was described by mean and standard deviation. Other demographic characteristics were categorized as follows: ethnic group including minority ethnic (including Mongolian, Manchu, Hui, Tibetan and other minority ethnic groups) and Hans, education level (middle school and below, high school and above), family members in current residence (one or two, three, four, more than four), migration range (inter-provincial and intra-provincial), the reason for migration (work or business, accompany, and others), whether to establish health record in current residence (no and yes), and medical insurance (no and yes).

\section{Statistical analysis}

All statistical analysis are performed using SPSS 24.0 and Stata 14.2. Percentages are used to describe the variables, and univariate logistic regression is used to explore the association between all variables and childbirth return. Two multivariable logistic regression models with an enter method are employed to examine the associations between social integration and childbirth return among migrant women. In model 1, we only include the indicators of the social integration. In model 2, we include some other potential confounders so as to examine whether social integration had significant influence on the choice of childbirth site when controlling for other factors. Those variables that have been proved to be associated with the health service use among the migrants (e.g., family members in current residence, Hukou, establishment of health records) and also collected in this study were included as control variables $[36,37]$. As for the explanatory variables, because social integration is a dynamic, multi-dimensional concept, we used the indicators which have been applied in many previous studies that are mostly cited and recognized to measure social integration in this study [10, 11, 33, 38]. According to the work book of the NIMPDMS in 2014, the weights of this study are only derived from strata and non-response weight, and all provincial urban belt and key cities were stratified, [35] and strata were finally determined by using the stratified multistage random sampling method. Within these, townships were selected as first-stage sampling units, and villages were selected from those townships. Finally, the individual respondents were selected from the selected village committee. We cannot cluster by townships because the information of townships is not available in the 2014 NIMPDMS. Thus, all analyses are conducted by incorporating strata and clustering in villages, and sampling weights are included.

\section{Results}

\section{The demographic characteristics}

Table 1 shows the basic information of the $3412 \mathrm{mi}$ grants. About $24.56 \%$ of internal migrant pregnant 
Table 1 The demographic characteristics of the sampling internal migrant pregnant women in China, 2014

\begin{tabular}{|c|c|c|c|c|c|c|}
\hline \multirow[t]{2}{*}{ Variables } & \multirow[t]{2}{*}{$N(\%)$} & \multicolumn{2}{|c|}{ Childbirth return } & \multicolumn{3}{|c|}{ Unadjusted model } \\
\hline & & No & Yes & OR & $95 \% \mathrm{Cl}$ & $P$ \\
\hline Observations & $3412(100)$ & $2583(75.44)$ & $829(24.56)$ & & & \\
\hline Age & $29.04 \pm 4.35^{\mathrm{a}}$ & $2583(75.44)$ & $829(24.56)$ & 0.941 & $0.911-0.972$ & 0.000 \\
\hline \multicolumn{7}{|l|}{ Ethnic group } \\
\hline Minority ethnic ${ }^{b}$ & $294(6.50)$ & $243(82.91)$ & $51(17.09)$ & 1.0 & & \\
\hline Hans & $3118(93.50)$ & $2340(74.92)$ & $778(25.08)$ & 1.624 & $0.980-2.690$ & 0.060 \\
\hline \multicolumn{7}{|l|}{ Education level } \\
\hline Middle school and below & $1728(48.47)$ & $1239(69.30)$ & $489(30.70)$ & 1.0 & & \\
\hline High school & $759(24.45)$ & $575(75.93)$ & $184(24.07)$ & 0.716 & $0.520-0.984$ & 0.040 \\
\hline Above high school & 925 (27.08) & $769(85.97)$ & $156(14.03)$ & 0.368 & $0.267-0.508$ & 0.000 \\
\hline \multicolumn{7}{|c|}{ Family members in current residence } \\
\hline$\leq 2$ & $290(9.51)$ & $130(46.28)$ & $160(53.72)$ & 1.0 & & \\
\hline 3 & $1951(51.81)$ & $1494(74.79)$ & $457(25.21)$ & 0.290 & $0.190-0.444$ & 0.000 \\
\hline 4 & $930(30.24)$ & 749 (82.77) & $181(17.23)$ & 0.179 & $0.113-0.284$ & 0.000 \\
\hline$>4$ & $241(8.44)$ & $210(85.94)$ & $31(14.06)$ & 0.141 & $0.066-0.302$ & 0.000 \\
\hline \multicolumn{7}{|l|}{ Hukou } \\
\hline Rural & $2707(78.74)$ & $1994(72.91)$ & $713(27.09)$ & 1.0 & & \\
\hline Urban & $705(21.26)$ & 589 (84.79) & $116(15.21)$ & 0.483 & $0.351-0.666$ & 0.000 \\
\hline \multicolumn{7}{|l|}{ Migration range } \\
\hline Inter-provincial| & $1730(32.83)$ & $1301(73.91)$ & $429(26.09)$ & 1.0 & & \\
\hline Intra-provincial $^{d}$ & $1682(67.17)$ & $1282(76.18)$ & $400(23.82)$ & 0.886 & $0.667-1.175$ & 0.401 \\
\hline \multicolumn{7}{|l|}{ Migration reason } \\
\hline Work and business & $2074(70.37)$ & $1612(78.78)$ & $462(21.22)$ & 1.0 & & \\
\hline Accompany & $1144(26.49)$ & $803(66.33)$ & $341(33.67)$ & 1.885 & $1.460-2.432$ & 0.000 \\
\hline Others & $194(3.14)$ & $168(77.41)$ & $26(22.59)$ & 1.083 & $0.437-2.686$ & 0.863 \\
\hline \multicolumn{7}{|l|}{ Establishment of health records } \\
\hline No & $2476(73.72)$ & $1809(72.53)$ & $667(27.47)$ & 1.0 & & \\
\hline Yes & $936(26.28)$ & $774(83.57)$ & $162(16.43)$ & 0.519 & $0.359-0.751$ & 0.001 \\
\hline \multicolumn{7}{|l|}{ Social medical insurance status } \\
\hline Uninsured & $470(16.54)$ & $386(84.23)$ & $84(15.77)$ & 1.0 & & \\
\hline Insured & $2942(83.46)$ & $2197(73.69)$ & $745(26.31)$ & 1.907 & $1.245-2.920$ & 0.003 \\
\hline
\end{tabular}

${ }^{\text {a }}$ Presented as mean \pm standard deviation

${ }^{\mathrm{b}}$ Minority ethnic including Mongolian, Manchu, Hui, Tibetan and other minority ethnic groups

'Inter-provincial refers to Chinese internal migrant who migrated just within one province,including among different cities and counties within a province

${ }^{d}$ Intra-provincial refers to Chinese internal migrant who migrated from one province to another province

women chose to have a childbirth return. The average age of the migrant pregnant women is 29.04 years, with a standard deviation of 4.35 years. The majority of the women are from rural areas (78.74\%),Hans (93.50\%), have an education level of middle school and below (48.47\%), inter-provincial migrants (32.83\%), with a migration reason for work and business (70.37\%), covered by medical insurance (83.46\%), and did not establish health record in the current residence (73.72\%). According to the result of univariate logistic regression, factors including age, ethnic group, education level, family members in current residence, Hukou, migration reason, establishment of health record, and medical insurance are significantly associated with childbirth return among migrant pregnant women.

\section{Social integration}

Social integration is measured by indicators of employment status, household monthly income, housing, duration of stay in current residence, and willingness to stay for a long time (Table 2). Of the respondents, $1408(44.80 \%)$ participants are employed. Regarding to household monthly income, the proportions of childbirth return of four income groups from low to high are $22.39,18.49,32.29,26.83 \%$, respectively. In 
Table 2 Childbirth return across different type of social integration status among internal migrant pregnant women in China, 2014

\begin{tabular}{|c|c|c|c|c|c|c|}
\hline \multirow[t]{2}{*}{ Variables } & \multirow[b]{2}{*}{$\mathrm{N}(\%)$} & \multicolumn{2}{|c|}{ Childbirth return } & \multicolumn{3}{|c|}{ Unadjusted model } \\
\hline & & No & Yes & OR & $95 \% \mathrm{Cl}$ & $P$ \\
\hline Observations & $3412(100)$ & $2583(75.44)$ & $829(24.56)$ & & & \\
\hline \multicolumn{7}{|c|}{ Economic integration status } \\
\hline \multicolumn{7}{|l|}{ Employment status } \\
\hline No & $2004(55.20)$ & $1526(73.70)$ & $478(26.30)$ & 1.0 & & \\
\hline Yes & $1408(44.80)$ & $1057(77.57)$ & $351(22.43)$ & 0.810 & $0.638-1.030$ & 0.085 \\
\hline \multicolumn{7}{|c|}{ Household monthly income ${ }^{a}$} \\
\hline Q1 & $1028(22.39)$ & $748(72.23)$ & $280(27.77)$ & 1.0 & & \\
\hline Q2 & $682(18.49)$ & $506(72.55)$ & $176(27.45)$ & 0.984 & $0.688-1.407$ & 0.930 \\
\hline Q3 & $1016(32.29)$ & $770(74.68)$ & $246(25.32)$ & 0.881 & $0.645-1.204$ & 0.427 \\
\hline Q4 & $686(26.83)$ & $559(81.01)$ & $127(18.99)$ & 0.610 & $0.411-0.905$ & 0.014 \\
\hline \multicolumn{7}{|l|}{ Housing type } \\
\hline Rent or borrow & $2426(76.86)$ & $1753(72.30)$ & $673(27.70)$ & 1.0 & & \\
\hline Own & $847(18.90)$ & $752(91.91)$ & 95 (8.09) & 0.230 & $0.148-0.356$ & 0.000 \\
\hline Others & 1394.23) & 78 (58.72) & $61(41.28)$ & 1.835 & $1.086-3.100$ & 0.023 \\
\hline \multicolumn{7}{|l|}{ Acculturation } \\
\hline \multicolumn{7}{|c|}{ Duration of stay in current residence } \\
\hline$<5$ years & $2337(65.70)$ & $1663(69.64)$ & $674(30.36)$ & 1.0 & & \\
\hline$\geq 5$ years & $1075(34.30)$ & $920(86.54)$ & $155(13.46)$ & 0.357 & $0.265-0.480$ & 0.000 \\
\hline \multicolumn{7}{|l|}{ Identification } \\
\hline \multicolumn{7}{|c|}{ Willingness to stay for a long time } \\
\hline No & $1197(38.05)$ & $776(65.37)$ & $421(34.63)$ & 1.0 & & \\
\hline Yes & $2215(61.95)$ & $1807(81.62)$ & $408(18.38)$ & 0.425 & $0.323-0.560$ & 0.000 \\
\hline
\end{tabular}

${ }^{\mathrm{a}}$ Quartile 1 (Q1) is the lowest (poorest) and Quartile $4(\mathrm{Q} 4)$ is the highest (richest) group

addition, $76.86 \%$ of participants' house are rented or borrowed, only $18.90 \%$ of participants have their own house in the current residence. Moreover, the rate of childbirth return among those whose housing is their own is $8.09 \%$, compared to $27.70 \%$ of those whose housing is rented or borrowed. Most of migrant pregnant women in the study have stayed in current residence for less than 5 years (65.70\%). About $61.95 \%$ of participants clearly expressed their willingness to stay for a longer time in current residence. Of whom, the rate of childbirth return is $18.38 \%$, compared to a rate of $34.63 \%$ among those who do not want to stay in current residence for a long time. According to the result of univariate logistic regression, factors including household monthly income, housing type, duration of stay in current residence, and willingness to stay in the current residence for long time are significantly associated with childbirth return among migrant pregnant women.

\section{The association between social integration status and} childbirth return

We present our results in two models so that we can better explore the association between social integration and childbirth return (Table 3 ). In Model 1, we only include social integration status. The results show that the association between social integration and the childbirth return among migrant pregnant women is statistically significant. In detail, the migrant pregnant women who do not have their own house in the current residence $(P=0.000, O R=0.351)$, have shorter duration of stay in current residence $(P=0.000, O R=0.449)$, have no willingness to stay in the current residence for a long time $(P=0.046, O R=0.731)$ are more likely to have a childbirth return. Even after all other variables were controlled, as shown in Model 2, the association between social integration and the childbirth return of migrant pregnant women is still significant.

Besides, factors including age, education level, family members in current residence, the reason for migration, whether established health record in the current residence, and social medical insurance are also associated with childbirth return (Table 3).

\section{Discussion}

The current study finds that $24.56 \%$ of the internal migrant pregnant women have childbirth return, which is lower than that among the migrant pregnant women in 
Table 3 Association between social integration and childbirth return among internal migrant women in China, 2014

\begin{tabular}{|c|c|c|c|c|c|c|}
\hline \multirow[t]{2}{*}{ Variables } & \multicolumn{3}{|c|}{ Regression Model 1} & \multicolumn{3}{|c|}{ Regression Model 2} \\
\hline & OR & $95 \% \mathrm{Cl}$ & $P$ & OR & $95 \% \mathrm{Cl}$ & $P$ \\
\hline \multicolumn{7}{|c|}{ Household monthly income ${ }^{a}$} \\
\hline Q1 & 1.0 & & & 1.0 & & \\
\hline Q2 & 1.050 & $0.718-1.535$ & 0.801 & 1.040 & $0.700-1.547$ & 0.845 \\
\hline Q3 & 1.021 & $0.731-1.426$ & 0.905 & 1.190 & $0.826-1.713$ & 0.350 \\
\hline Q4 & 0.971 & $0.626-1.505$ & 0.894 & 1.402 & $0.886-2.218$ & 0.149 \\
\hline \multicolumn{7}{|l|}{ Housing type } \\
\hline Rent or borrow & 1.0 & & & 1.0 & & \\
\hline Own & 0.311 & $0.196-0.493$ & 0.000 & 0.351 & $0.207-0.595$ & 0.000 \\
\hline Others & 2.038 & $1.180-3.521$ & 0.011 & 1.608 & $1.007-2.568$ & 0.047 \\
\hline \multicolumn{7}{|c|}{ Duration of stay in current residence } \\
\hline$<5$ years & 1.0 & & & 1.0 & & \\
\hline$\geq 5$ years & 0.413 & $0.301-0.566$ & 0.003 & 0.449 & $0.322-0.626$ & 0.000 \\
\hline \multicolumn{7}{|c|}{ Willingness to stay for a long time } \\
\hline No & 1.0 & & & 1.0 & & \\
\hline Yes & 0.634 & $0.471-0.853$ & 0.003 & 0.731 & $0.537-0.995$ & 0.046 \\
\hline Age & & & & 1.007 & $0.974-1.040$ & 0.694 \\
\hline \multicolumn{7}{|l|}{ Education level } \\
\hline Middle school and & & & & 1.0 & & \\
\hline High school & & & & 0.735 & $0.531-1.019$ & 0.065 \\
\hline Above high school & & & & 0.369 & $0.238-0.572$ & 0.000 \\
\hline \multicolumn{7}{|c|}{ Family members in current residence } \\
\hline$\leq 2$ & & & & 1.0 & & \\
\hline 3 & & & & 0.271 & $0.170-0.432$ & 0.000 \\
\hline 4 & & & & 0.146 & $0.088-0.240$ & 0.000 \\
\hline$>4$ & & & & 0.122 & $0.055-0.269$ & 0.000 \\
\hline \multicolumn{7}{|l|}{ Hukou } \\
\hline Rural & & & & 1.0 & & \\
\hline Urban & & & & 0.871 & $0.567-1.337$ & 0.527 \\
\hline \multicolumn{7}{|l|}{ Migration reason } \\
\hline Work and business & & & & 1.0 & & \\
\hline Accompany & & & & 1.748 & $1.311-2.332$ & 0.000 \\
\hline Others & & & & 1.128 & $0.438-2.905$ & 0.803 \\
\hline \multicolumn{7}{|c|}{ Establishment of health records } \\
\hline No & & & & 1.0 & & \\
\hline Yes & & & & 0.678 & $0.470-0.978$ & 0.038 \\
\hline \multicolumn{7}{|c|}{ Social medical insurance status } \\
\hline Uninsured & & & & 1.0 & & \\
\hline Insured & & & & 2.048 & $1.280-3.278$ & 0.003 \\
\hline
\end{tabular}

Beijing (59.2\%) [39]. There are several possible reasons why the childbirth return rate among migrant women in Beijing is higher than that of the national average level. First, Beijing is the capital of China, and high-quality maternal healthcare service resources are intensively allocated in Beijing, which attracts a large number of pregnant women from all over the country to use maternal care, including childbirth, in Beijing [40]. This thus the 
accessibility to maternal care is reduced for the migrant women. Second, medical expenses in Beijing are higher than the average level in the whole country [41]. It is hard for the migrants with low income to use highexpense childbirth services in Beijing.

This study indicates that over $70 \%$ of the migrant pregnant women give birth in the current residence, and this percentage is still on the rise. This is a positive trend but would probably increase the burden of post-partum care for the migrant mothers and babies, especially for the healthcare practitioners in the community health centers in the inflow areas. This finding implies for the healthcare practitioners in the inflow areas to establish health records for migrant pregnant women, so as to provide continuous and timely post-partum care for the migrant mothers and babies. In addition, the primary healthcare practitioners should also carry out comprehensive health education related to the potential risk of residential instability during pregnancy and importance of the post-partum care for the mothers and babies, to further increase the percentage of childbirth in the current residence and also a better postpartum recovery among the migrant pregnant women. As a long-term countermeasure, to establish a more integrated pregnancy record system for migrant pregnant women, and then the migrant pregnant women starting care in inflow site could continue accessing care if they return to their hometown, so as to improve health outcomes whether they give childbirth in the inflow area or at their hometown.

Some previous studies found that social integration was beneficial for some health.

outcomes among migrants [33, 42, 43]. This study also demonstrates an association between social integration and childbirth return among internal migrant women in China. The social integration is found to be negatively associated with childbirth return. The higher the level of the social integration is, the less possibility the migrant fertile women have a childbirth return. This association is multifaceted, lies in the dimensions of economic integration, acculturation, and identification. This finding implies that improving the localization situation (local adaption) and also income so as to promote the social integration might be helpful for the migrant women to use maternal care in the inflow areas.

As for the dimension in the economic integration, this study finds that migrant women who do not have their own house in the inflow areas are more likely to have childbirth return. For migrant pregnant women who do not have their own house in the inflow areas, and living in renting houses with poor sanitary and environmental conditions, they are more willing to return their hometown to get better home care when giving a birth to a child. In addition, those who have a house in the inflow areas will be easier to get formal or informal maternal postpartum care, which is similar to some previous studies [44].

Acculturation and identification are both significantly associated with the childbirth return among migrant women. The results show that the shorter the migrant women stay in inflow areas, the more likely they are to have a childbirth return. According to a study by Zhou, [10] the length of the duration of stay in the inflow areas, to a certain extent, can reflect the social adaptation of the migrants. That is to say, the migrant women who stay for a longer time, may have higher degree in social adaption, and also be more likely to get social support in the inflow areas, which are useful for the migrant women to use maternal care in the inflow areas [45]. With respect to self-identity, this study finds that migrant pregnant women who are willing to live in inflow areas for a long time are less likely to have a childbirth return. Identification can comprehensively reflect the integration status of migrants to the local population [36]. The migrant women with lower identification may have poorer adaptability to the local residents. As a result, the migrant pregnant women are more likely to return their hometown for childbirth. Measures to improve the identification are helpful for the migrant women to use maternal care in the current residence. For example, early antenatal classes for migrant women would assist them acquire supports in the current residence, which would be useful to make the migrant pregnant women feel more comfortable to give birth in the current residence.

Apart from social integration status, some other factors are also found to be associated with childbirth return among migrant women. The migrant pregnant women who have a lower education level are more likely to have childbirth returns. This might be due to that higher education can enable migrant women to acquire more maternal health care knowledge, including the risk of mobility during pregnancy [46]. As shown in the study, the more family members live together in the inflow areas, the less likely the migrant women are to return their hometown for childbirth. The reason might be that the large family size in current residence, to some extent, may indicate that the migrants have gradually adapted to the local life and culture. In addition, our study finds that the migrant pregnant women who outmigrate for accompany (the women who migrate because their husband or partner), who do not establish health records in the current residence, and who are covered by any kind of social medical insurance scheme are more likely to have childbirth returns.

This study has some limitations. First, the data of the study were based on self-reported measures which might lead to recall bias. Secondly, due to the limitations of the questionnaire, we only selected some indicators of economic integration, acculturation, and identification, and 
some other potential factors (e.g., language) were not included, which may not comprehensively reflect social integration status of the internal migrant pregnant women. Finally, we did not use qualitative methods to explore the push and pull factors for women's choice of childbirth place, as well as an in-depth study of the postnatal outcomes of migrant pregnant women who give birth in hometown or in inflow areas, which would be remedied in the follow-up studies.

\section{Conclusion}

This study finds that nearly a quarter of the migrant women return their hometown for childbirth. A significant association between social integration status and childbirth return is demonstrated among internal migrant women in China, especially lies in the dimensions of economic integration, acculturation, and identification. Migrant women with low social integration (with low income, the duration of stay in the inflow area less than 5 years, unwilling to stay for a long time) are more likely to return their hometown to give birth. This finding implies for interventions to improve the localization situation might be helpful for the migrant women to use maternal care in the inflow areas. Based on these findings, targeting promotion in social integration among migrant pregnant women, giving full consideration to their difference in culture, identification and other aspects, should be given to improve the utilization rate of maternal care in the current residence. Early antenatal classes for migrant women would assist them acquire supports in the current residence, which would be useful to make the migrant pregnant women feel more comfortable to give birth in the current residence. This study also finds some other factors, including education, family members in current residence, the reason for migration, health record, and social medical insurance, are associated with the choice of childbirth location.

\section{Supplementary information}

Supplementary information accompanies this paper at https://doi.org/10. 1186/s12913-020-05783-5.

Additional file 1: Figure S1. Flowchart of selecting process for the participants.

\section{Acknowledgements}

We thank the officials of local health agencies and all participants and staff at the study sites for their cooperation.

\section{Authors' contributions}

$C Z$, LD and $X L$ conceived the idea. XT, YF, YW, JC participated in the statistical analysis and interpretation of the results. LD and XL drafted the manuscript. CZ and MS gave many valuable comments on the draft and also edited the manuscript. All authors read and approved the final manuscript.

\section{Funding}

We are grateful for funding support from the National Science Foundation of China (71974117, 71774104, 71473152), Chinese Medical Board (CMB-16-257), Cheeloo Youth Scholar Grant, and Shandong University (IFYT1810,

2012DX006). The funding body has no role in the design of the study and collection, analysis, and interpretation of data and in writing the manuscript.

\section{Availability of data and materials}

The data used in this study are from the National Health and Family Planning Commission of China. The authors cannot share the data without approval from the National Health and Family Planning Commission of China. Those who want to request the data are encouraged to contact the corresponding author of this paper.

\section{Ethics approval and consent to participate}

The study protocol for this study was approved by the Ethical Committee of Shandong University School of Public Health and was in accordance with the 1964 Helsinki declaration and its later amendments or comparable ethical standards. The investigation was performed after the acquisition of written informed consents from all of the participants.

Consent for publication

Not applicable.

\section{Competing interests}

The authors declare that they have no competing interests.

\section{Author details}

${ }^{1}$ Centre for Health Management and Policy, School of Public Health, Cheeloo College of Medicine, Shandong University, Jinan 250012, China. ${ }^{2}$ School of Public Health, Fudan University, Shanghai 200032, China. ${ }^{3} \mathrm{NHC}$ Key Laboratory of Health Economics and Policy Research (Shandong University), 44 Wen-hua-xi Road, Jinan 250012, Shandong, China.

Received: 8 February 2020 Accepted: 30 September 2020

Published online: 07 October 2020

\section{References}

1. China Migrant Population Development report.2018.Available at: http:// www.chinaldrk.org.cn/wjw/\#/achievement/publication/ded7ec35-00d4-40c68f73-1094df9714472018. (Accessed by 31 Jul 2020).

2. Yuan C. Study on the health problems of floating population in the process of urbanization. Shanxi Youth. 2016;21:10-1 (In Chinese).

3. Jia S, Wang C. Study on the health problems of China's floating population. Human Recourse Soc Sci. 2014;18:330 (In Chinese).

4. Chen J. Internal migration and health: re-examining the healthy migrant phenomenon in China. Soc Sci Med. 2011;72(8):1294-301.

5. Xiao Y. Analysis of public health management of migrant population. China Health Industry. 2017;14(05):39-40 (In Chinese).

6. You X, Tan H, Hu S, et al. Effects of preconception counseling on maternal health care of migrant women in China: a community-based, cross-sectional survey. BMC Pregnancy Childbirth. 2015;15(1):55.

7. Han S, Chen W, Ling L. The influence of migrant characteristics on the utilization of basic public health services of migrant pregnant women. Modern Prev Med. 2017:44(1):94-8 (In Chinese).

8. Jang SH. Medical transnationalism: Korean Immigrants' medical tourism to South Korea [M]. Lanham: Rowman \& Littlefield; 2018.

9. Alba R, Nee V. Rethinking assimilation theory for a new era of immigration. Int Migr Rev. 1997;31(4):826.

10. Zhou H. Measurement and theoretical thinking of social integration of floating population. Popul Res. 2012;36(03):27-37 (In Chinese).

11. Yang J. Indicator system of the social integration for floating population in the inflow areas. Popul Econ. 2010;2:64-70 (In Chinese).

12. Kemppainen L, Kemppainen T, Skogberg N, et al. Immigrants' use of health care in their country of origin: the role of social integration, discrimination and the parallel use of health care systems. Scand J Caring Sci. 2018;32(2): 698-706.

13. Kim H. Social integration and heath policy issues for international marriage migrant women in South Korea. Public Health Nurs. 2010;27(6):561-70. 
14. Tunstall H, Pickett $K$, Johnsen S. Residential mobility in the UK during pregnancy and infancy: are pregnant women, new mothers and infants 'unhealthy migrants'? Soc Sci Med. 2010;71(4):786-98.

15. Bell ML, Belanger K. Review of research on residential mobility during pregnancy: consequences for assessment of prenatal environmental exposures. J Expo Sci Environ Epidemiol. 2012;22(5):429-38.

16. Jones RC, Hughes CR, Wright D, et al. Early house moves,indoor air,heating methods and asthma. Respir Med. 1999;93:919-22.

17. Dolk H, Vrijheid M. The impact of environmental pollution on congenital anomalies. Br Med Bull. 2003;68(1):25-45.

18. Boerleider AW, Wiegers TA, Manniën J, et al. Factors affecting the use of prenatal care by non-western women in industrialized western countries: a systematic review. BMC Pregnancy Childbirth. 2013;13:81. https://doi.org/10. 1186/1471-2393-13-81. PMID: 23537172; PMCID: PMC3626532.

19. Kirby JB, Kaneda T. Access to health care: does neighborhood residential instability matter? J Health Soc Behav. 2006;47(2):142-55.

20. Duchon LM, Shinn WM. The relationship of residential instability to medical care utilization among poor mothers in New York City. Med Care. 1999; 37(12):1282-93.

21. Kusuma YS, Kumari R, Kaushal S. Migration and access to maternal healthcare: determinants of adequate antenatal care and institutional delivery among socio-economically disadvantaged migrants in Delhi, India. Tropical Med Int Health. 2013;18(10):1202-10.

22. Stephenson R, Matthews Z. Maternal health-care service use among ruralurban migrants in Mumbai, India. Asia-Pacific Popul J / United Nations. 2004;19(1):39-60.

23. Meng $\mathrm{H}$. Research on the integration of basic medical insurance for urban and rural residents under the background of new household registration system[D]. Nanning, Guangxi University; 2017. (In Chinese).

24. Song $\mathrm{H}$. Accelerate the reform of rural household registration system to promote the integrated development of both urban and rural areas. Res Agric Modernization. 2016;37(6):1011.

25. National Bureau of Statistics of China. Statistical Monitoring Report of 2016 China Women's Development Program (2011-2020). 2017. http://www.stats. gov.cn/tjsj/zxfb/201710/t20171026_1546608.html. Accessed 2 Oct 2020.

26. Yang $X$. Study on differences in utilization of basic public health services between permanent registration and migrant population and influencing factors. Chin J Public Health. 2018;34(06):781-5 (In Chinese).

27. Bergmark R, Barr D, Garcia R. Mexican immigrants in the US living far from the border may return to Mexico for health services. J Immigr Minor Health. 2010;12(4):610-4.

28. Jiang $\mathrm{SH}$. Factors associated with Korean immigrants medical tourism to the homeland. Am J Health Behav. 2017:4(41):461-70.

29. Song $X$, Zou G, Chen W, et al. Health service utilization of rural-to-urban migrants in Guangzhou, China: does employment status matter? Tropical Med Int Health. 2017;22(1):82-91.

30. Peng Y, Chang W, Zhou H, Liang W, et al. Factors associated with healthseeking behavior among migrant workers in Beijing, China. BMC Health Serv Res. 2010;10(1):69.

31. Horton S, Cole S. Medical returns: seeking health care in Mexico. Soc Sci Med. 2011;72(11):1846-52.

32. Berkman LF, Glass T, Brissette I, et al. From social integration to health: Durkheim in the new millennium. Soc Sci Med. 2000;51(6):843-57.

33. Peng BL, Ling L. Association between rural-to-urban migrants' social medical insurance, social integration and their medical return in China: a nationally representative cross-sectional data analysis. BMC Public Health. 2019;19(1):86.

34. Lin $Y$, Zhang $Q$, Chen W, et al. Association between Social Integration and Health among Internal Migrants in ZhongShan, China. PLoS One. 2016;11(2): e0148397. Published 2016 Feb 10. https://doi.org/10.1371/journal.pone. 0148397.

35. National Populational and Family Planning Commission. Handbook of dynamic monitoring on migrants in China (2015). Beijing: National Population and Family Planning Commission; 2014.

36. Han SQ, Chen W, Ling L. Impact of migrant characteristics on maternal health care utilization among migrant pregnant women in China. Modern Prev Med. 2017;44(01):94-8 (In Chinese)

37. Guo J, Yang HL, Liu LL. Status quo and determinants of awareness on basic public health service among migrant population. Chin J Public Health. 2019; 35(01):63-6 (In Chinese).
38. Berry JW. Immigration, acculturation, and adaptation. Appl Psychol. 1997; 46(1):5-34.

39. Wu D. Study on the spatial optimization of high-quality medical resources in Beijing under the background of non-capital functional disorganization[D]. Beijing, Capital university of Economics and Business; 2016. (In Chinese).

40. Bao Y, Gao X, Xu J, et al. Investigation on health care status of migrant women uring pregnancy and childbirth in xicheng district, Beijing. Soft Sci Health. 2011;25(06):388-9 (In Chinese).

41. Ji Y, Zhao X, Wang Z, et al. Mobility patterns and associated factors among pregnant internal migrant women in China: a cross-sectional study from a National Monitoring Survey. BMC Pregnancy Childbirth. 2018;18(1):165.

42. Lin Y, Zhang Q, Chen W, et al. The social income inequality, social integration and health status of internal migrants in China. Int J Equity Health. 2017:16(1):139.

43. Dong X. Prevention and home care for postpartum depression. Med Aesthetics. 2014;12:510 (In Chinese).

44. De Jesus M, Xiao C. Cross-border health care utilization among the Hispanic population in the United States: implications for closing the health care access gap. Ethn Health. 2013;18(3):297-314.

45. Aurelius G, Blomqvist ER. Pregnancy and delivery among immigrants. Scand J Soc Med. 1978:6(1):43-8.

46. Trostel P, Walker I. Education and work. Educ Econ. 2000;4(14):377-99.

\section{Publisher's Note}

Springer Nature remains neutral with regard to jurisdictional claims in published maps and institutional affiliations.
Ready to submit your research? Choose BMC and benefit from:

- fast, convenient online submission

- thorough peer review by experienced researchers in your field

- rapid publication on acceptance

- support for research data, including large and complex data types

- gold Open Access which fosters wider collaboration and increased citations

- maximum visibility for your research: over $100 \mathrm{M}$ website views per year

At BMC, research is always in progress.

Learn more biomedcentral.com/submissions 